\title{
The Effect of Dynamic Neuromuscular Stabilization (DNS) on the Respiratory Function of Subjects with Forward Head Posture (FHP)
}

\author{
Won-Sik Bae, PT, $\mathrm{PhD}^{\dagger}$ \\ Department of Physical Therapy, Kyungnam College of Information \& Technology
}

Received: July 13, 2021 / Revised: July 20, 2021 / Accepted: August 2, 2021

(C) 2021 J Korean Soc Phys Med

\begin{abstract}
| Abstract |
PURPOSE: The purpose of this study was to apply dynamic neuromuscular stabilization (DNS) to subjects with forward head posture (FHP) and to compare its effects on respiratory function as against the conventional neck stabilization exercise and neck stretching and extensor strengthening exercises.
\end{abstract}

METHODS: The whole-body posture measurement system was used to measure the degree of FHP, and a spirometer and a respiratory gas analyzer were used to measure the respiratory function. After the intervention was completed, the changes over time were analyzed in the DNS group, the neck stabilization exercise group, and the neck stretching and extensor strengthening exercise group. The inter-group difference in the changes was also analyzed. A repeated ANOVA was performed to compare the respiratory function according to the period between the three groups, and the least significant difference (LSD) method was used for the post hoc test.

RESULTS: After the 6-week exercise period, respiratory

$\dagger$ Corresponding Author: Won-Sik Bae f452000@naver.com, https://orcid.org/0000-0003-2308-3729

This is an Open Access article distributed under the terms of the Creative Commons Attribution Non-Commercial License (http://creativecommons.org/licenses/by-nc/3.0) which permits unrestricted non-commercial use, distribution, and reproduction in any medium, provided the original work is properly cited. functions, such as forced vital capacity (FVC), forced expiratory volume for 1 second (FEV1), forced expiratory volume for $1 \mathrm{sec} /$ forced vital capacity (FEV1/FVC), maximum oxygen intake $\left(\mathrm{VO}_{2} \mathrm{max}\right)$, and the volume of expired gas (VE), significantly improved according to the period ( $\mathrm{p}<.05)$, but no inter-group differences were found. CONCLUSION: DNS is an effective training method, and can be applied along with neck stabilization exercise and neck stretching and extensor strengthening exercises, which are widely used in clinical practice, to people with FHP who cannot directly perform neck exercises to improve their respiratory function.

Key Words: Forward head posture, Pressure bio-feedback unit, Dynamic neuromuscular stabilization exercise, Respiratory function

\section{Introduction}

Forward head posture (FHP) is a common postural fault that occurs frequently in students or office workers who sit at their desks for a long time. In people with FHP, the head moves forward from the sagittal plane, out of the neutral alignment with the spine and is positioned in front of the torso. This is considered the most commonly observed postural modification in FHP [1].

Abnormal postures, such as FHP, cause an inefficient 
contraction of the abdominal muscles, resulting in reduced lung capacity due to the impaired function of the diaphragm and its reduced movement, which in turn leads to a decrease in the strength of the respiratory muscles [2,3]. A decrease in lung volume and lung capacity due to incorrect posture may affect alveolar ventilation and dilatation of the thoracic cage, resulting in weakening of the respiratory muscles. Incorrect posture can also increase the muscle tone of the sternocleidomastoid muscle, causing the thoracic cage to be lifted upward, and as a result, the movement of the lower back area is reduced, which in turn reduces the ventilation function of the diaphragm $[4,5]$.

Recently, several exercises using small tools have been introduced to improve FHP. These tools are commonly used to improve the proprioceptive sense in the suboccipital muscles of the neck with a high muscle spindle density by providing an unstable support surface [6]. Through the neck stabilization exercise using a pressure biofeedback device, the superficial muscles of the neck flexors, namely sternocleidomastoid and the scalenus anterior muscles, can maintain a relaxed state, while the deep flexor muscles of the upper cervical vertebrae, namely the longus colli and the longus capitis muscles are strengthened, which enables flexion and maintenance of the skull and the neck. Because these exercises are performed on an unstable surface, they activate proprioceptive stimulation to wake up the brain and speed up information processing, which improves the agility, reflexes, and coordination of the body.

In addition, there have been several attempts to improve FHP through breathing exercises $[2,7,8]$. Dynamic neuromuscular stabilization (DNS) proposed by the Czech physiotherapist Prof. Paver Kolar is a rehabilitation approach that optimizes the movement system based on the principles of developmental kinesiology [9]. Named the "Integrated spinal stabilization system" (ISSS) by Prof. Kolar, this exercise method uses the diaphragm, the internal oblique muscles, the transverse abdominis muscle, the pelvic floor muscles, superficial abdominal muscles, and the thoracic cage muscles simultaneously to control the postural stabilization cylinder belt (PSCB), thereby ensuring optimal intra-abdominal pressure [10]. In other words, together with the diaphragm, these muscles regulate the optimal intra-abdominal pressure, providing spinal stiffness and dynamic stabilization. It also constitutes the deep core, operating under an automatic and potential feed-forward control mechanism [11].

The DNS method extends the lower abdominal region instead of the thoracic cage during inhalation while pushing and holding the navel forward and downward so that the diaphragm and the deep spinal stabilizing muscles can be contracted simultaneously, and the intra-abdominal pressure can be increased. DNS consists of well-controlled simultaneous contractions of the deep flexors and extensors in the neck and the back regions as well as of the pelvic floor muscles, the diaphragm, the lower back, and the abdominal muscles. This can also improve the postural abnormality in the neck area, benefiting people with FHP [11].

Although many studies have compared the DNS exercise with the back stabilization exercises, there are few studies which have assessed the effect of DNS on respiratory function in FHP. Therefore, the purpose of this study was to investigate the effect of DNS on the respiratory function of subjects with FHP.

\section{Methods}

\section{Participants}

Forty-five adults (average 22 age) with FHP, who resided in Busan Metropolitan City, South Korea participated in this study. These participants were divided into three groups of 15 people each through simple randomization by drawing lots. The experimental group performed DNS, control group A performed the neck stabilization exercise, and control group B performed neck stretching and extensor strengthening exercises.

Before the start of the experiment, consent was obtained 
from the participants that they have understood the purpose of the study and were willing to participate voluntarily. A pre-test was performed to select subjects with FHP. The inclusion criteria for subjects were as follows: those who did not have a history of congenital or acquired musculoskeletal disease (confirmed by a verbal history check), those who did not have respiratory system-related diseases (confirmed by a verbal history check), those who showed a distance of $1 \mathrm{~cm}$ or more from the center line in the measurement taken by the whole body posture measurement system, and those who fully understood the purpose and procedures of the study and agreed to participate in it. Those who failed to participate in the exercise more than once during the experiment were excluded. This study was approved by the Institutional Review Board of Busan Catholic University (IRB No. CUPIRB-2016-052).

\section{Assessment methods}

1) Postural assessment

The global postural assessment system (GPS400, Chinesport, Italy) was used to diagnose FHP. The GPS is a computerized photographic postural assessment in which the side view of the subject was photographed with a camera in an upright position with his knees straight, his arms placed side by side on the torso, and his head in a comfortable position, gazing in front. People with a distance of $1 \mathrm{~cm}$ or more between the humerus bone and the vertical line that goes up to the external acoustic meatus, based on the determination criteria of the New York State Posture Standards, were selected to participate in this study [12].

\section{2) Respiratory function assessment}

Using a spirometer (SPIROVIT SP-1, SCHILLER AG, Switzerland), lung function parameters, including the forced vital capacity (FVC) during exhalation, forced expiratory volume for 1 second (FEV1), and the ratio of
FEV1 to FVC (FEV1/FVC) were measured. The subject inhaled to his maximum capacity in a sitting position, put the spirometer in his mouth, and performed forced exhalation for 5 seconds. This process was repeated thrice to calculate the average value of the measurements.

3) Respiratory gas assessment

A respiratory gas analyzer (CS-200 ERGO-SPIRO, SCHILLER AG, Switzerland) was used to measure the cardiopulmonary function during exercise. The subject proceeded from walking to running on the treadmill, while wearing a mask containing the CS-200 ERGO-SPIRO device according to the Bruce Protocol. The maximum oxygen intake $\left(\mathrm{VO}_{2} \mathrm{max}\right)$ and the volume of expired gas (VE) were measured using the equipment. This measurement was discontinued when the predicted maximum heart rate was reached, when the specified speed could not be maintained, or the subject requested to stop the exercise due to cardiovascular symptoms or fatigue. This took about 10 minutes.

\section{Exercise methods}

1) Dynamic neuromuscular stabilization

The DNS was performed according to the following procedure: the hip joint of the subject was bent at $90^{\circ}$ in the supine position, and a pressure biofeedback device (Stabilizer, Chattanooga Group, INC., USA) was placed under the subject's lower back. When the pressure displayed on the manometer indicated $60 \mathrm{mmHg}$, the anterior, lateral and posterior abdomen was expanded during inhalation to increase the pressure by $10 \mathrm{mmHg}$, and then the subject kept inhaling through the nose and exhaling through the mouth, while maintaining the pressure. During inhalation, the lower ribs moved laterally, the sternum moved toward the lower abdomen, and it was ensured that the chest and the navel did not move toward the head, the pelvis was fixed, and the upper abdominal region was not extended 
Table 1. Neck Stabilization Exercise Program

\begin{tabular}{cc}
\hline Exercise Intensity & Time \\
\hline $20 \sim 22 \mathrm{mmHg}$ & 10 second*10 repetitions \\
$20 \sim 24 \mathrm{mmHg}$ & 10 second*10 repetitions \\
$20 \sim 26 \mathrm{mmHg}$ & 10 second*10 repetitions \\
$20 \sim 28 \mathrm{mmHg}$ & 10 second*10 repetitions \\
$20 \sim 30 \mathrm{mmHg}$ & 10 second*10 repetitions \\
\hline
\end{tabular}

more than the lower abdominal region [13]. The ratio of inhalation and exhalation was 5 seconds each at a ratio of 1:1 for 2 minutes, followed by a rest for one minute, and this procedure was repeated 10 times. This exercise was performed for 30 minutes a day, three times a week, for six weeks [11].

\section{2) Neck stabilization exercise}

The neck stabilization exercise was performed using a pressure biofeedback device and increasing the pressure by $2 \mathrm{mmHg}$ up to $20 \sim 30 \mathrm{mmHg}$ in the following manner: the exercise was carried out for 10 seconds at the static maintenance strength for each reference value, followed by a rest for 3 seconds, and this procedure was repeated 10 times, with a step-wise increment of $2 \mathrm{mmHg}$ up to $30 \mathrm{mmHg}$. This process was defined as one set, with a rest for one minute, and three sets of this exercise were performed for 32 minutes a day, three times a week, for six weeks [14]. Specific details are indicated in Table 1.

3) Neck stretching and extensor strengthening exercises

The McKenzie neck stretching exercise consists of seven movements. In this study, five movements were performed. The excluded movements were pulling the head backward in a sitting position and pulling the chin inward in a supine position. The intensity of the exercise was maintained for 7 seconds at the maximum static strength, followed by a rest for 3 seconds, followed by the next movement. This procedure was repeated 10 times, which was defined as one set. One minute was given for rest between sets. Two sets of this exercise were performed for 25 minutes a day, three times a week, for six weeks [15].

The neck extensor strengthening exercise was performed according to the following procedure: the subject took a prone position on a treatment table with the upper body extended out of the treatment table up to the papillary line. While fixing the legs and pelvis with both hands holding the opposite shoulders, the subject lifted both the head and the upper body to the same level as the treatment table, and then held this position for 10 seconds, followed by a rest for 3 seconds. This procedure was repeated 10 times, which was defined as one set. Two sets of this exercise were performed for 5 minutes a day, three times a week, for six weeks [16].

\section{Statistical analysis}

The data collected in this study were analyzed using the SPSS 21.0 program for Windows, and the significance level (a) for the statistical test was set to .05 . The general characteristics of the study subjects were calculated with descriptive statistics, and a one-way ANOVA was performed to confirm the homogeneity between groups. A repeated ANOVA was performed to compare the respiratory functions according to the period between the three groups. A one-way ANOVA was performed to compare the inter-group variations in respiratory functions three weeks and six weeks after the intervention, and the LSD method was used for the post hoc test.

\section{Results}

\section{General Characteristics of the Subjects}

Table 2 shows the general characteristics of the study subjects. There was no significant difference between the experimental group and the control groups before the experiment; therefore, the three groups were considered homogeneous. 
Table 2. General Characteristics of the Subjects

\begin{tabular}{cccccc}
\hline General characteristics & $\begin{array}{c}\text { Experimental group } \\
(\mathrm{n}=15)\end{array}$ & $\begin{array}{c}\text { Control A group } \\
(\mathrm{n}=15)\end{array}$ & $\begin{array}{c}\text { Control B group } \\
(\mathrm{n}=15)\end{array}$ & Fault value & p-value \\
\hline Age $(\mathrm{yrs})$ & $21.73 \pm 2.58$ & $22.47 \pm 2.10$ & $21.67 \pm 1.54$ & .660 & .522 \\
Height $(\mathrm{cm})$ & $168.73 \pm 9.33$ & $167.20 \pm 7.23$ & $166.60 \pm 8.07$ & .266 & .767 \\
Weight $(\mathrm{kg})$ & $63.07 \pm 15.29$ & $60.80 \pm 10.72$ & $67.40 \pm 12.43$ & 1.006 & .374 \\
FHP $(\mathrm{cm})$ & $2.91 \pm 1.19$ & $2.84 \pm .93$ & $3.03 \pm 1.03$ & .121 & .887 \\
\hline
\end{tabular}

Experimental group : Dynamic neuromuscular stabilizing exercise group

Control A group : Neck muscle-stabilizing exercise group

Control B group : Neck muscle stretching \& extensor strengthening exercise group

FHP : Forward head posture

Table 3. Change in the Forced Vital Capacity

(unit: $\ell$ )

\begin{tabular}{|c|c|c|c|c|c|c|}
\hline & Before & $\begin{array}{c}\text { After } \\
\text { 3-weeks }\end{array}$ & $\begin{array}{c}\text { After } \\
\text { 6-weeks }\end{array}$ & $\begin{array}{c}\text { Time } \\
\text { (Fault value) }\end{array}$ & $\begin{array}{c}\text { Group } \\
\text { (Fault value) }\end{array}$ & $\begin{array}{l}\text { Time*Group } \\
\text { (Fault value) }\end{array}$ \\
\hline Experimental group $(\mathrm{n}=15)$ & $3.97 \pm .88^{\mathrm{a}}$ & $4.13 \pm .91^{\mathrm{b}}$ & $4.21 \pm .84^{\mathrm{b}}$ & & & \\
\hline Control Agroup $(n=15)$ & $3.54 \pm .68^{\mathrm{a}}$ & $3.75 \pm .90^{\mathrm{a}}$ & $4.06 \pm .92^{b}$ & $13.671^{*}$ & .905 & 2.066 \\
\hline Control B group $(\mathrm{n}=15)$ & $3.46 \pm .59^{\mathrm{a}}$ & $3.90 \pm .85^{\mathrm{a}}$ & $3.96 \pm .85^{\mathrm{b}}$ & & & \\
\hline Fault value & 2.106 & .725 & .291 & & & \\
\hline $\mathrm{p}$-value & .134 & .490 & .749 & & & \\
\hline
\end{tabular}

${ }^{*} \mathrm{p}<.05, \mathrm{a}<\mathrm{b}$

Table 4. Change in the Forced Expiratory Volume in One Second

(unit: $\ell$ )

\begin{tabular}{|c|c|c|c|c|c|c|}
\hline & Before & $\begin{array}{c}\text { After } \\
\text { 3-weeks }\end{array}$ & $\begin{array}{c}\text { After } \\
\text { 6-weeks }\end{array}$ & $\begin{array}{c}\text { Time } \\
\text { (Fault value) }\end{array}$ & $\begin{array}{c}\text { Group } \\
\text { (Fault value) }\end{array}$ & $\begin{array}{l}\text { Time*Group } \\
\text { (Fault value) }\end{array}$ \\
\hline Experimental group $(n=15)$ & $3.14 \pm .78^{\mathrm{a}}$ & $3.57 \pm .78^{b}$ & $3.62 \pm .70^{\mathrm{b}}$ & & & \\
\hline Control Agroup $(\mathrm{n}=15)$ & $2.84 \pm .73^{\mathrm{a}}$ & $3.07 \pm .68^{\mathrm{a}}$ & $3.41 \pm .74^{\mathrm{b}}$ & $24.063^{*}$ & 1.082 & 2.025 \\
\hline Control B group $(n=15)$ & $2.89 \pm .56^{\mathrm{a}}$ & $3.31 \pm .65^{\mathrm{b}}$ & $3.46 \pm .61^{\mathrm{c}}$ & & & \\
\hline Fault value & .827 & 1.849 & .402 & & & \\
\hline $\mathrm{p}$-value & .444 & .170 & .671 & & & \\
\hline
\end{tabular}

\section{Changes in Respiratory Function}

1) Changes in FVC

Table 3 shows the changes in FVC for each group as a result of the 6-week interventions. There was a significant increase according to the intervention period $(\mathrm{p}<.05)$, but neither the interaction effect between the periods nor the inter-group difference was significant $(p>.05)$.
However, after 6 weeks, the mean value was highest in the DNS group.

\section{2) Changes in FEV1}

Table 4 shows the changes in FEV1 for each group as a result of the 6-week interventions. There was a significant increase according to the intervention period $(p<.05)$, but neither the interaction effect between the 
Table 5. Change in the Forced Expiratory Volume in One Second/Forced Vital Capacity

(unit: \%)

\begin{tabular}{ccccccc}
\hline & Before & $\begin{array}{c}\text { After } \\
\text { 3-weeks }\end{array}$ & $\begin{array}{c}\text { After } \\
\text { 6-weeks }\end{array}$ & $\begin{array}{c}\text { Time } \\
\text { (Fault value) }\end{array}$ & $\begin{array}{c}\text { Group } \\
\text { (Fault value) }\end{array}$ & $\begin{array}{c}\text { Time*Group } \\
\text { (Fault value) }\end{array}$ \\
\hline Experimental group $(\mathrm{n}=15)$ & $81.29 \pm 13.11^{\mathrm{a}}$ & $86.56 \pm 9.01^{\mathrm{a}}$ & $87.94 \pm 7.70^{\mathrm{b}}$ & & & \\
Control Agroup $(\mathrm{n}=15)$ & $79.75 \pm 9.31^{\mathrm{a}}$ & $82.51 \pm 7.44^{\mathrm{a}}$ & $84.42 \pm 6.22^{\mathrm{a}}$ & $5.571^{*}$ & 1.352 & .211 \\
Control B group $(\mathrm{n}=15)$ & $84.26 \pm 7.88^{\mathrm{a}}$ & $86.26 \pm 6.75^{\mathrm{a}}$ & $88.36 \pm 7.23^{\mathrm{a}}$ & & & \\
\hline Fault value & .770 & 1.189 & 1.050 & & & \\
p-value & .469 & .316 & .359 & & & \\
\hline
\end{tabular}

${ }^{*} \mathrm{p}<.05, \mathrm{a}<\mathrm{b}$

Table 6. Change in the $\mathrm{VO}_{2} \max$

(unit: $\ell / \min$ )

\begin{tabular}{ccccccc}
\hline & Before & $\begin{array}{c}\text { After } \\
\text { 3-weeks }\end{array}$ & $\begin{array}{c}\text { After } \\
\text { 6-weeks }\end{array}$ & $\begin{array}{c}\text { Time } \\
\text { (Fault value) }\end{array}$ & $\begin{array}{c}\text { Group } \\
\text { (Fault value) }\end{array}$ & $\begin{array}{c}\text { Time*Group } \\
\text { (Fault value) }\end{array}$ \\
\hline Experimental group $(\mathrm{n}=15)$ & $1.92 \pm .53^{\mathrm{a}}$ & $2.08 \pm .57^{\mathrm{a}}$ & $2.28 \pm .56^{\mathrm{b}}$ & & & .832 \\
Control A group $(\mathrm{n}=15)$ & $1.92 \pm .46^{\mathrm{a}}$ & $2.01 \pm .44^{\mathrm{a}}$ & $2.04 \pm .49^{\mathrm{a}}$ & $7.161^{*}$ & .152 & \\
Control B group $(\mathrm{n}=15)$ & $1.93 \pm .54^{\mathrm{a}}$ & $2.12 \pm .50^{\mathrm{a}}$ & $2.14 \pm .71^{\mathrm{a}}$ & & & \\
\hline Fault value & .044 & .205 & .361 & & \\
p-value & .957 & .816 & .699 & & \\
\hline
\end{tabular}

${ }^{*} \mathrm{p}<.05, \mathrm{a}<\mathrm{b}$

periods nor the inter-group difference was significant $(\mathrm{p}$ $>.05)$. However, the largest change was observed in the DNS group.

\section{3) Changes in FEV1/FVC ratio}

Table 5 shows the changes in the FEV1/FVC ratio for each group as a result of the 6-week interventions. There was a significant increase according to the intervention period $(\mathrm{p}<.05)$, but neither the interaction effect between the periods nor the inter-group difference was significant $(\mathrm{p}>.05)$.

\section{4) Changes in $\mathrm{VO}_{2}$-max}

Table 6 shows the changes in the $\mathrm{VO}_{2}$-max for each group as a result of the 6-week interventions. There was a significant increase according to the intervention period $(p<.05)$, but neither the interaction effect between the periods nor the inter-group difference was significant $(p$ $>.05)$.

\section{5) Changes in VE}

Table 7 shows the changes in VE for each group as a result of the 6-week interventions. There was a significant increase according to the intervention period $(p<.05)$, but neither the interaction effect between the periods and the group nor the difference between the groups was significant $(p>.05)$. However, the largest change was observed in the DNS group.

\section{Discussion}

An increase in the severity of FHP has been shown to have a significant correlation with a decrease in respiratory muscle strength in patients with neck pain which causes weakness in the deep flexors and extensors of the neck and a decrease in the range of motion [17]. As such, incorrect posture causes abnormal breathing due to the weakening of the respiratory muscles, and if left unattended for an extended period may lead to chronic respiratory 


\begin{tabular}{|c|c|c|c|c|c|c|}
\hline & Before & $\begin{array}{c}\text { After } \\
\text { 3-weeks }\end{array}$ & $\begin{array}{c}\text { After } \\
\text { 6-weeks }\end{array}$ & $\begin{array}{c}\text { Time } \\
\text { (Fault value) }\end{array}$ & $\begin{array}{c}\text { Group } \\
\text { (Fault value) }\end{array}$ & $\begin{array}{l}\text { Time*Group } \\
\text { (Fault value) }\end{array}$ \\
\hline Experimental group $(\mathrm{n}=15)$ & $52.24 \pm 15.94^{\mathrm{a}}$ & $61.04 \pm 19.15^{b}$ & $65.28 \pm 20.05^{\mathrm{b}}$ & & & \\
\hline Control Agroup $(\mathrm{n}=15)$ & $46.94 \pm 13.01^{\mathrm{a}}$ & $53.47 \pm 14.05^{\mathrm{b}}$ & $55.94 \pm 13.05^{\mathrm{b}}$ & $18.379^{*}$ & .894 & .383 \\
\hline Control B group $(n=15)$ & $50.01 \pm 16.18^{\mathrm{a}}$ & $57.10 \pm 14.62^{b}$ & $58.39 \pm 18.49^{b}$ & & & \\
\hline Fault value & .224 & .694 & .939 & & & \\
\hline $\mathrm{p}$-value & .800 & .506 & .399 & & & \\
\hline
\end{tabular}

${ }^{*} \mathrm{p}<.05, \mathrm{a}<\mathrm{b}$

disease. Moreover, as the normal expansion of the lungs becomes difficult, a decrease in lung capacity, total lung capacity, partial pressure, etc. may occur, and the diffusion capacity between oxygen and carbon dioxide at the blood-air barrier may also decrease [18]. As the muscle tone of the sternocleidomastoid muscle increases, the thoracic cage is lifted upward, and the mobility of the back and lumbar regions decreases, resulting in poor ventilation capacity of the diaphragm. Such an inefficient imbalance reduces not only the muscular strength of the respiratory muscles but also the ventilation function of the lungs, which is required for physical activities [4]. Therefore this study was undertaken to investigate the effect of each exercise (DNS, neck stabilization exercise, and neck stretching and extensor strengthening exercises) performed for six weeks on respiratory function, in 45 subjects with FHP.

In cases where incorrect postures, such as FHP, have a negative effect on respiratory function by causing a misalignment of the body and changes in the length of the respiratory muscles [17], breathing exercises can be applied to improve respiratory function and respiratory muscle strength [19]. In an earlier study Okuro et al. [2] have reported that severe FHP results in deterioration of pulmonary function and difficulties in inhalation. Consequently, patients with severe FHP use oral respiration as a compensatory mechanism to reduce the resistance during pulmonary breathing.

Measurement of respiratory functions in the present study revealed that there were significant improvements in FVC, FEV1, and FEV1/FVC after the 6-week intervention in every exercise group. Almeida et al. [20] reported a significant correlation between FHP and lung function in asthma patients. In a study on the comparison of lung capacity between subjects with FHP and those with normal posture, Han et al. [7] reported that the subjects with FHP showed reduced FVC, FEV1 and FEV1/FVC. Bae et al. [21] studied the effects of artificial posture changes for FHP and neutral posture on breathing and found that when subjects with FHP were made to take a neutral posture artificially, FVC, FEV1 and FEV1/FVC were all lower in the FHP than in the artificial neutral posture. On the other hand, when subjects with neutral posture were made to take an FHP artificially, FVC, FEV1 and FEV1/FVC were all lower in the artificial FHP than in the neutral posture. These results indicated that respiratory functions are compromised in those with FHP.

In an earlier study related to interventions in subjects with FHP, Kang et al. [22] reported that FVC and FEV1 increased in the sternocleidomastoid and the scalenus muscles of the neck after a neck stretching exercise and a neck flexion feedback exercise were applied to subjects with FHP. In a study on the effects of the McKenzie stretching exercise on FHP and respiratory function, Kim [23] reported a significant increase in FVC and FEV1 after four weeks of intervention. In a study on the effect of the abdominal breathing exercises on respiratory function 
and respiratory muscle strength in adults with FHP, Lee [19] reported a significant increase in FVC and FEV1 after four weeks of the abdominal breathing exercises in the FHP group.

In the present study, significant increases in FVC, FEV1, and FEV1/FVC were observed in all exercise groups, which showed that not only the neck stabilization exercise and neck stretching and extensor strengthening exercises, which are generally applied to people with FHP, but also DNS helped improve respiratory function. This finding suggests that FHP caused a deformation of the thoracic cage and weakening of the respiratory muscles resulting in decreased lung function. The above results suggest that people with FHP can improve their lung function solely by changing to a neutral posture and by strengthening the respiratory muscles and inhalation capacity through the application of correct posture and breathing training. This can benefit not only patients with FHP, but also patients with musculoskeletal disorders and the general public can achieve better results for the prevention and treatment of FHP.

$\mathrm{VO}_{2}$-max significantly improved in all the exercise groups after six weeks of exercise as compared to before the interventions. As a measure of the effectiveness of aerobic exercise, $\mathrm{VO}_{2}$-max is an objective evaluation tool widely used to evaluate endurance ability by focusing on oxygencarrying functions, including the respiratory-circulatory system [24]. $\mathrm{VO}_{2}$-max is defined as the maximum amount of oxygen per unit time that the human body can intake and use during its activity and refers to the ability of the active group to utilize oxygen. Therefore, the relationship between the oxygen consumption system and the active muscle mass is an important data indicator of human work ability.

According to the study by Davis et al. [25], continuous exercise for three days per week improves $\mathrm{VO}_{2}$-max by $20 \%$ to $30 \%$ after training even in people without any postural or other abnormalities. In a study of subjects with FHP conducted by Jang [18], $\mathrm{VO}_{2}$-max increased more in the breathing exercise group than in the progressive resistive exercise group. Lee \& Ju [26] reported that as the severity of FHP increased, $\mathrm{VO}_{2}$-max decreased, and the respiratory circulation function was lower in the group with FHP than in the group with a neutral posture. Therefore, correct posture alignment would be necessary to improve breathing ability. In the present study, both the experimental group and the control groups showed an increase in $\mathrm{VO}_{2}$-max after three weeks and six weeks of exercise, but no significant inter-group differences were observed.

VE significantly improved after six weeks of exercise in all exercise groups. Nam [27] reported that the forward reclining posture moves the internal organs below the diaphragm forward, reduces the breathing pattern using the upper chest, and decreases the ventilation rate per minute. Han et al. [7] reported that the maximum volume of voluntarily expired gas was higher in the subjects with neutral positions than in the subjects with FHP. Also in the present study, both the experimental group and the control groups showed an increase in VE after three weeks and six weeks of exercise, but there was no significant inter-group difference. VE depends on the contractile force of the lungs and the diameter of the airways and is closely related to $\mathrm{VO}_{2}$-max. The increase in $\mathrm{VE}$ after exercise is a secondary phenomenon related to the increase of $\mathrm{VO}_{2}$ -max, which is likely to result from an increase in oxygen transport due to the accelerated gas exchange in the upper part of the expanded lungs.

Postural change is a variable that affects respiratory functions. Changes in the respiratory muscle activity due to posture change can be induced by the elasticity of the soft tissues around the bones and the thoracic cage and the strength of the muscles that support the movement of the respiratory system [28]. Chen et al. [29] defined the changes in respiratory function associated with postural change as follows : abdominal muscle tension increases to support the abdominal volume, resulting in decreased 
abdominal wall elasticity, and contractions of the diaphragm, intercostal muscles, and accessory muscles of respiration cause the thoracic cage to expand significantly, as a result of which lung function is enhanced.

One of the limitations of this study was that it was difficult to generalize the results of this experiment because the head was not controlled to be fixed uniformly when measuring lung function with the spirometer. Further, the study subjects were limited to adults in their twenties. In the future, a follow-up study should be conducted to confirm the lasting effect of the DNS exercise.

\section{Conclusion}

This study was conducted to investigate the effects of DNS on respiratory functions in subjects with FHP.

The results of the study revealed a correlation between FHP and respiratory function. This study also showed that in cases where neck exercises could not be performed directly on subjects with FHP, breathing exercises using the diaphragm had a similar beneficial effect as a direct neck exercise. Therefore, DNS can be utilized along with the neck stabilization exercise and neck extension and extensor strengthening exercises, which are widely used in clinical practice, to improve respiratory functions in for people who are unable to perform neck exercises.

\section{Acknowledgements}

This study is a summary of Wonsik Bae's doctoral dissertation (2017).

\section{References}

[1] Dunleavy K, Goldberg A. Comparison of cervical range of motion in two seated postural conditions in adults 50 or older with cervical pain. J Man Manip Ther. 2013;21(1):33-9.
[2] Okuro RT, Morcillo AM, Ribeiro MÂ, et al. Mouth breathing and forward head posture: effects on respirat ory biomechanics and exercise capacity in children. J Bras Pneumol. 2011;37(4):471-9.

[3] Silveira WD, Mello FC, Guimarães FS, et al. Postural alterations and pulmonary function of mouth-breathing children. Braz J Otorhinolaryngol. 2010;76(6):683-6.

[4] Correa EC, Berzin F. Mouth breathing syndrome: cervical muscles recruitment during nasal inspiration before and after respiratory and postural exercises on Swiss ball. Int J Pediatr Otorhinolaryngol. 2008;72(9):1335-43.

[5] Lima LC, Baraúna MA, Sologurem MJ, et al. Postural alterations in children with mouth breathing assessed by computerized biophotogrammetry. J Appl Oral Sci. 2004;12(3):232-7.

[6] Liu JX, Thornell LE, Pedrosa-Domellof F. Muscle spindles in the deep muscles of the human neck: a morphological and immunocytochemical study. J Histochem Cytochem. 2003;51(2):175-86.

[7] Han JT, Park SJ, Kim YJ, et al. Effects of forward head posture on forced vital capacity and respiratory muscles activity. J Phys Ther Sci. 2016;28(1):128-31.

[8] Santos TV, Ruas G, Sande de LA, et al. Influence of forward leaning and incentive spirometry on inspired volumes and inspiratory electromyographic activity during breathing exercises in healthy subjects. J Electromyogr Kinesiol. 2012;22(6):961-7.

[9] Kolar P. Facilitation of agonist-antagonist coactivation by reflex stimulation methods in: Craig Liebenson: Rehabilitation of the spine-A practitioner's manual (2nd ed). Baltimore. Lippincott Williams \& Wilkins. 2007.

[10] Kolar P, Sulc J, Kyncl M, et al. Postural function of the diaphragm in persons with and without chronic low back pain. J Orthop Sports Phys Ther. 2012;42(4):352-62.

[11] Frank C, Kobesova A, Kolar P. Dynamic neuromuscular stabilization \& sports rehabilitation. Int J Sports Phys Ther. 2013;8(1):62-73.

[12] Harman K, Hubley-Kozey CL, Butler H. Effectiveness 
of an exercise program to improve forward head posture in normal adults: a randomized, controlled 10-week trial. J Man Manipulative Ther. 2005;13(3):163-76.

[13] Kolar P, Kučera M, Lewit K, et al. Clinical rehabilitation. Praha. Alena Kobesova. 2013.

[14] Jull GA, Falla D, Vicenzino B, et al. The effect of therapeutic exercise on activation of the deep cervical flexor muscles in people with chronic neck pain. Man Ther. 2009;14(6):696-701.

[15] McKenzie R. Treat your own neck (5th ed). Waikanae. Spinal publications. 2011.

[16] Park JH, Moon OK, Wang JS, et al. The effects of continuous antagonist strengthening and Evjenth-Hamberg stretching on improvement of forward head posture. Journal of the Korea Entertainment Industry Association. 2013;7(2):109-15.

[17] Kapreli E, Vourazanis E, Strimpakos N. Neck pain causes respiratory dysfunction. Med Hypotheses. 2008;70(5): 1009-13.

[18] Jang C. The effects of breathing exercise on forward head posture. Doctor's Degree. Daegu University. 2010.

[19] Lee JC. The effects of abdominal respiratory exercise by forward head posture adult's respiratory function and respiratory muscle strength. Master's Degree. Daegu University. 2015.

[20] Almeida VP, Guimaraes FS, Moco VJ, et al. Correlation between pulmonary function, posture, and body composition in patients with asthma. Rev Port Pneumol.
2013;19(5):204-10.

[21] Bae WS, Lee KC, Park SW, et al. Effect of the changes in forward head posture and neutral head posture on respiratory. J Korean Soc Integr Med. 2017;5(1):67-74.

[22] Kang JI, Jeong DK. The effect of exhalation breathing exercise on respiratory synergist muscle activity and pulmonary functions in patients with forward head posture. J Korean Phys Ther. 2016;28(2):149-54.

[23] Kim SY. The effects of Mckenzie exercise on forward head posture and respiratory function. Master's Degree. Pusan Catholic University. 2014.

[24] Whaley MH, Brubaker PH, Otto RM, et al. ACSM's guidelines for exercise testing and prescription (7th ed). New York. Lippincott Williams \& Wilkins. 2005.

[25] Davis GM, Kofsky PR, Kelsey JC, et al. Cardiorespiratory fitness and muscular strength of wheelchair users. Can Med Assoc J. 1981;125(12):1317-23.

[26] Lee MH, Joo M. Correlations between craniovertebral angle(CVA) and cardiorespiratory function in young adults. J Korean Soc Phys Med. 2014;9(1):107-13.

[27] Nam KW. Cardiovascular and pulmonary physical therapy. Seoul. Panmuneducation. 2012.

[28] Alfred PF, Elias JA, Fishman JA, et al. Fishman's pulmonary diseases and disorders (4th ed). New York. Mc Graw Hill. 2008.

[29] Chen CF, Lien IN, Wu MC. Respiratory function in patients with spinal cord injuries. Paraplegia. 1990; 28(2):81-6. 